\title{
O006: Development of a method to simulate practical use conditions of hygienic handrubs
}

\author{
J Rutter ${ }^{1}$, DR Macinga ${ }^{1,2^{*}}$ \\ From 2nd International Conference on Prevention and Infection Control (ICPIC 2013) \\ Geneva, Switzerland. 25-28 June 2013
}

\section{Introduction}

The World Health Organization has recognized the shortcomings of current standards for evaluating the in vivo efficacy of hand hygiene products, and has called for methods which are "realistic under practical conditions".

\section{Objectives}

The objective of this study was to develop a method to evaluate the efficacy of alcohol-based handrubs, which reflects the mode of hand contamination typical in healthcare settings to provide an accurate assessment of product performance under in-use conditions.

\section{Methods}

Stainless steel discs $1 \mathrm{~cm}$ in diameter were contaminated with $10 \mu \mathrm{l}$ of a liquid suspension of $S$. aureus ATCC 6538 (8 $\log$ CFU/ml) and allowed to dry. Discs were stored in a humidity chamber at $50 \% \mathrm{RH}$ for up to 72 hours prior to use. Hands were contaminated by firmly pressing each fingerpad to a contaminated disc for 2 seconds. Two fingers on each hand were sampled individually by kneading in a neutralizer solution for $30 \mathrm{sec}-$ onds to obtain pre-treatment counts. A hand hygiene intervention was performed after which the remaining fingers were sampled to obtain post-treatment values. Recovered bacteria were quantified and mean log reductions per finger were calculated.

\section{Results}

S. aureus was stable on stainless steel discs for several days. Transfer and recovery of $S$. aureus from fingers was highly reproducible both between the fingers of individual subjects and between different subjects (mean recovery $=5.9 \pm 0.2 \log$ CFU per finger pad; $N=65$ ). The organism was stable on the fingers with no die off for at least 40 minutes. A 15 second non-antimicrobial handwash, $0.5 \mathrm{ml}$, and $1 \mathrm{ml}$ of an alcohol based hand rub achieved $\log$ reductions of $3.2 \pm 0.5,2.9 \pm 1.3$ and $3.7 \pm 1.0$, respectively. Consistent with other hygienic hand rub methods, intra-subject variability was low and inter-subject variability was high.

\section{Conclusion}

Contamination of the fingers via contact with a dry surface appears to be a simple and highly reproducible means of evaluating the efficacy of hand hygiene products under practical use conditions. Furthermore, this method utilizes a relevant marker organism, and simulates the primary mode of hand contamination in healthcare settings. Finally, the sampling method may be applied to the clinical setting to perform Phase 3 field studies, to investigate prevention of cross-transmission of pathogens through use of a hygienic handrub.

\section{Disclosure of interest}

None declared.

\section{Author details}

${ }^{1}$ GOJO Industries, Inc., Akron, USA. ${ }^{2}$ Northeast Ohio Medical University, Rootstown, USA.

Published: 20 June 2013

doi:10.1186/2047-2994-2-S1-O6

Cite this article as: Rutter and Macinga: 0006: Development of a method to simulate practical use conditions of hygienic handrubs. Antimicrobial Resistance and Infection Control 2013 2(Suppl 1):06.

${ }^{1}$ GOJO Industries, Inc., Akron, USA

Full list of author information is available at the end of the article

(c) 2013 Rutter and Macinga; licensee BioMed Central Ltd. This is an Open Access article distributed under the terms of the Creative 